\title{
Interação e aprendizagem em Sites de Redes Sociais: uma análise a partir das concepções sócio-históricas de Vygotsky e Bakhtin
}

\section{Learning and Interaction in Social Networking Sites: an analysis based on Vygotsky's and Bakhtin's socio-historical concepts}

Cíntia Regina Lacerda Rabello*

Universidade Federal do Rio de Janeiro

Rio de Janeiro - Rio de Janeiro / Brasil

RESUMO: Este trabalho tem como objetivo refletir sobre como as contribuições das concepções sócio-históricas de Vygotsky e de Bakhtin relativas à atitude responsiva, dialogismo, zona de desenvolvimento proximal e conceitos espontâneos e científicos podem trazer luz aos processos de interação, colaboração e aprendizagem em Sites de Redes Sociais (SRSs) de forma a contribuir para a realização de processos educacionais em contextos digitais que conduzam a uma maior participação e construção colaborativa do conhecimento. $\mathrm{O}$ artigo relata um estudo exploratório acerca da utilização do SRS Facebook no ensino de língua inglesa na educaçao de nível superior com o objetivo de expandir as interações realizadas na sala de aula.

PALAVRAS-CHAVE: interação; aprendizagem; sites de rede social; Facebook.

ABSTRACT: This paper aims to discuss how the contributions of Vygotsky's and Bakhtin's socio-historical concepts concerning responsive attitude, dialogism, zone of proximal development and spontaneous and scientific concepts can bring light to the interaction, collaboration and learning processes in Social Networking Sites (SNSs) in order to contribute to educational processes in digital contexts that lead to greater participation and collaborative construction of knowledge. The paper reports on an exploratory study on the use of Facebook in English language teaching in higher education aiming at expanding students' interactions beyond the physical classroom.

KEYWORDS: interaction; learning; social networking site; Facebook.

*cintia_rabello@hotmail.com 


\section{Introdução}

As tecnologias digitais, cada vez mais inseridas no nosso cotidiano, trazem enormes transformações para a sociedade, tais como a alteração da relação espaço-temporal permitida pelo ambiente virtual, e o desenvolvimento de novas práticas comunicacionais e relações sociais marcadas pelos recursos eletrônicos (LEMOS, 2003). Nesse cenário, as Tecnologias da Informação e da Comunicação (TICs) desempenham um papel fundamental na produção e distribuição de informação, assim como nas relações entre os indivíduos no espaço virtual, fato que abre diversas possibilidades do ponto de vista social e educacional, mas geram também grandes desafios, como o de promover processos educacionais verdadeiramente inovadores, capazes de romper com modelos centralizadores e de transmissão de conhecimento ainda muito presentes em contextos presenciais.

O novo paradigma tecnológico emergente com a introdução da Web 2.0 permite aos usuários exercerem um papel mais ativo na busca, compartilhamento e produção de informação e construção de conhecimento no ambiente virtual. Paralelamente, o avanço de novas ferramentas on-line permite que se vislumbrem novas abordagens educacionais voltadas para a interação e colaboração entre alunos e professores em comunidades virtuais de aprendizagem no ciberespaço fundamentadas, na organização de redes sociais.

No cenário contemporâneo de transformaçôes, com necessidade constante de inovação em processos de construção do conhecimento, a educação encontra um ambiente favorável para uma mudança de paradigmas. A aprendizagem on-line, possibilitada pelos avanços das TICs e ferramentas de comunicação mediadas pelo computador (CMC), está mudando radicalmente os ambientes e contextos de aprendizagem. Variadas ferramentas voltadas para a educação formal, tais como os Sistemas de Gerenciamento da Aprendizagem (SGAs) e outras, criadas sem propósitos educacionais, tais como as mídias sociais, como, por exemplo, YouTube, e os sites de redes sociais (SRSs), como Facebook e Twitter, possibilitam a construção de conhecimento e aprendizagem no ciberespaço, não restringindo mais o processo educacional a um tempo ou espaço específico, abrindo novas possibilidades e perspectivas para a educação formal e informal ao ampliar as possibilidades de interação e construção colaborativa de conhecimento.

Fenômeno contemporâneo de grande aceitação entre jovens e adultos, os SRSs constituem espaço de compartilhamento e colaboração, permitindo 
a geração de capital social (RECUERO, 2009) e desenvolvimento da inteligência coletiva (LÉVY, 2010). Nesse sentido, as possibilidades de interação entre os participantes da rede social no ciberespaço constituem um grande potencial para o desenvolvimento de processos de aprendizagem formal e informal ao expandir o ambiente de aprendizagem para além do espaço físico da sala de aula presencial.

Considerando a aprendizagem um processo essencialmente social, que se dá na interação com o outro por meio da linguagem e nas relações dialógicas entre os sujeitos, podemos entender os SRSs como espaços de diálogo que demandam uma atitude responsiva dos participantes, de forma que os interagentes transformem e sejam transformados pelos contextos interacionais. Contudo, é necessário investigar como esses recursos podem ser apropriados para os contextos educacionais e quais os benefícios que eles podem trazer para a aprendizagem.

Este artigo tem como objetivo refletir sobre a utilização de um SRS como ambiente virtual de aprendizagem na expansão da sala de aula presencial no ensino superior e investigar como o ambiente favoreceu a aprendizagem dos alunos. $\mathrm{O}$ trabalho investiga como as concepções sóciohistóricas de Lev Vygotsky (1930/1998, 1926/2001) e Mikhail Bakhtin (1953/2010, 1929/2010) relativas à atitude responsiva, dialogismo, zona de desenvolvimento proximal e conceitos espontâneos e científicos podem trazer luz aos processos de interação, colaboração e aprendizagem em ambientes mediados pela tecnologia, de forma a contribuir para a realização de processos educacionais em contextos digitais que conduzam a uma maior participação e construção colaborativa do conhecimento.

Das cinco seções em que se organiza o trabalho, a primeira destina-se a apresentar a definição de SRS e a sua potencialidade para a aprendizagem colaborativa e em rede. Em seguida, fazemos uma breve revisão de conceitos sócio-históricos de Vygotsky e Bakhtin que podem contribuir para a compreensão do potencial de SRSs no contexto educacional, de forma a promover um processo de ensino e aprendizagem voltado para a interação entre os participantes e a construção colaborativa do conhecimento. Na terceira seção, apresentamos uma experiência de utilização de um SRS no ensino superior e, em seguida, discutimos alguns resultados desta experiência com base nas contribuiçôes dos dois autores. Por fim, tecemos as considerações finais em busca de processos de ensino e aprendizagem no ensino superior que, ao fazerem uso das novas tecnologias, principalmente os SRSs, busquem e 
promovam uma mudança de paradigmas no campo educacional, estimulando o diálogo e a colaboração para além do espaço da sala de aula presencial.

\section{Entendendo Sites de Redes Sociais (SRSs) e seu potencial para a aprendizagem}

Ao falarmos em redes sociais estamos nos referindo basicamente a relaçõos entre pessoas. Segundo Recuero (2009), a metáfora da rede nos permite observar as conexões estabelecidas entre os indivíduos dentro do grupo social. Assim, a rede é constituída por dois elementos: os atores (os nós da rede) e suas conexões (interações ou laços sociais).

As redes sociais na Internet (ou redes sociais virtuais) são as conexões estabelecidas por pessoas no ciberespaço, utilizando softwares sociais (sites ou plataformas de redes sociais), tais como Facebook, Orkut, Linked-in, entre outros. Segundo Buzzeto-More, os SRSs constituem

[...] aplicativos de computador que possibilitam um arranjo complexo de nós conectados (pessoas) através de ferramentas para armazenar e apresentar informação, bem como comunicar, conectar e interagir com outras pessoas (BUZZETO-MORE, 2012, p. 64) ${ }^{1}$.

Similarmente, Boyd e Ellison definem os SRSs como

[...] um serviço baseado na web que permite aos indivíduos (1) construir um perfil público ou semipúblico dentro de um sistema determinado, (2) articular uma lista de outros usuários com quem eles compartilham uma conexão, e (3) visualizar e percorrer suas listas de conexões e aquelas feitas por outras pessoas dentro do sistema (BOYD; ELLISON, 2007, p. 211). ${ }^{2}$

Segundo as autoras, algumas das características dos principais SRS compreendem: (1) a criação de um perfil que poderá ser visualizado por toda a rede de relacionamentos (ou parte dela) dentro do SRS; (2)

\footnotetext{
${ }^{1}$ Tradução nossa do original: "[...] computer applications that support the complex arrangements of connected nodes (people) with tools for storing and presenting information as well as communicating, connecting, and interacting with others."

${ }^{2}$ Tradução nossa do original: "[...] web-based services that allow individuals to (1) construct a public or semi-public profile within a bounded system, (2) articulate a list of other users with whom they share a connection, and (3) view and traverse their list of connections and those made by others within the system."
} 
possibilidade de novas conexôes através da rede de relacionamentos (amigos); (3) comunicação (aberta ou privada) entre os participantes da rede; (4) compartilhamento de arquivos de imagem, som, texto e vídeo; (5) a criação de grupos de discussão ou comunidades para o debate de temas específicos.

As autoras complementam que, embora os diversos SRSs possuam diferentes características e ferramentas, o componente crucial desses ambientes compreende a exibição pública das conexões na rede de relacionamentos, ou seja, por meio de tais ferramentas faz-se possível visualizar as conexões, antes ocultas, entre os indivíduos e, assim, ampliar as possibilidades de novas conexões no ambiente virtual (Ibid.).

Apesar de não terem sido desenvolvidos para fins educacionais, como os SGAs, essas ferramentas têm sido bastante exploradas dentro do campo educacional na criação de ambientes virtuais de aprendizagem, principalmente no ensino superior, constituindo objeto de diversas pesquisas (SELWYN, 2009; WANG et al., 2012; MEISHAR-TAL et al., 2012; KENT, 2013, TOWNER; MUÑOZ, 2012; VIDAL et al., 2011). Sob a perspectiva sócio-interacionista de aprendizagem, os SRSs se apresentam como ambientes propícios à construção colaborativa do conhecimento por meio das interaçốes sociais, troca e compartilhamento de informações e criação coletiva. Atualmente, os SRSs dispõem de diferentes ferramentas que ampliam as possibilidades de utilização em contextos educacionais, tais como a formação de grupos específicos, públicos ou privados, onde é possível compartilhar, além de hyperlinks e imagens, arquivos em diferentes formatos (Word, PDF, Power Point, etc.), promover debates e enquetes, realizar debates síncronos por meio da ferramenta de bate-papo, entre outros.

Nesse sentido, Siemens e Weller (2011) caracterizam os SRS como ferramentas construtivistas que atendem aos objetivos de novos métodos de participação no ensino superior capazes de impactar na autonomia do estudante, contrapondo a utilização dos SRS ao modelo de educação tradicional, estruturado na figura central do professor e no fluxo unilateral de conteúdo. Os autores destacam também o enorme potencial educacional dessas ferramentas, e propõem sua utilização em detrimento de plataformas educacionais formais como os SGAs, uma vez que estes, muitas vezes, tendem a reproduzir o modelo autoritário da sala de aula. Os SRS, por sua vez,

[...] podem beneficiar os aprendizes uma vez que encorajam o diálogo entre pares, promovem o compartilhamento de recursos, facilitam a colaboração e desenvolvem habilidades de comunicação. Estas são 
características da aprendizagem on-line que os sistemas de gerenciamento da aprendizagem convencionais têm se esforçado para alcançar na última década com a adoção intensiva na educação superior. Ainda assim, os SRS parecem ter alcançado tal êxito com extraordinária velocidade e facilidade (SIEMENS; WELLER, 2011, p. 164-165). ${ }^{3}$

Assim, vislumbram-se diferentes usos educacionais para essas plataformas, de forma a encorajar o diálogo e o compartilhamento de informações e recursos para a aprendizagem formal e informal. No ensino superior, os SRSs podem ser usados não somente na educação on-line (totalmente a distância ou semipresencial), como também na modalidade de blended learning (Ensino Híbrido), quando há uma interseção entre a educação presencial e a distância por meio do uso de tecnologias digitais, de forma a expandir o espaço da sala de aula, ampliando as possibilidades de interação e construção de conhecimento.

\section{Ensino e aprendizagem em SRSs: diálogos com as concepções sócio-históricas de Vygotsky e Bakhtin}

São diversas as semelhanças entre as obras de Lev Vygotsky (18961934) e Mikhail Bakhtin (1895-1975). Ambos, fortemente influenciados pelo materialismo histórico-dialético, desenvolveram diferentes estudos em relação à linguagem e à consciência humana. Apesar de diferentes propósitos, suas teorias encontram campo comum, dialogando entre si em diferentes aspectos, como, por exemplo, a utilização do método dialético como metodologia de trabalho e o questionamento do modelo positivista nas ciências humanas (FREITAS, 1997). Ao se debruçarem sobre os processos de interação e diálogo, ambos trazem grandes contribuições para o campo educacional, principalmente no que se refere aos processos de ensino e aprendizagem em diferentes contextos, podendo ser aplicadas, inclusive, nos contextos digitais, onde os processos de comunicação e interação mediados por computador exercem papel fundamental para a aprendizagem.

\footnotetext{
${ }^{3}$ Tradução nossa do original: "[...] can be a real benefit for learners as they encourage peer-to-peer dialogue, promote the sharing of resources, facilitate collaboration, and develop communication skills. These are all features of online learning that conventional learning management systems (LMSs) have struggled to realize over the past decade of intensive adoption in higher education. Yet SNSs seem to have accomplished this with remarkable ease and speed."
} 


\section{O papel do diálogo e da atitude responsiva na aprendizagem}

Bakhtin se dedicou às questôes da linguagem e do discurso, sendo um dos aspectos centrais da sua obra o papel do outro para a constituição do próprio sujeito. De acordo com Freitas, "o eu para Bakhtin só existe numa relação com o outro. [...] Suas próprias palavras são um resultado de incorporação de palavras alheias" (FREITAS, 1997, p. 9). Em Marxismo e Filosofia da Linguagem, Bakhtin/Voloshinov (1959/2010) discorre sobre o processo de enunciação e a importância do outro:

$\mathrm{Na}$ realidade, toda palavra comporta duas faces. Ela é determinada tanto pelo fato de que procede de alguém, como pelo fato de que se dirige para alguém. Ela constitui justamente o produto da interação do locutor e do ouvinte. Toda palavra serve de expressão a um em relação ao outro. Através da palavra, defino-me em relação ao outro, isto é, em última análise, em relação à coletividade (BAKHTIN/VOLOSHINOV, 1959/2010, p. 117).

Entendendo a enunciação como o produto da interação entre dois indivíduos situados de forma social, cultural e histórica, temos que a palavra (enunciado) sempre se dirige a um interlocutor, constituindo um território comum entre ele e o locutor, procedendo de alguém e se dirigindo para alguém, constituindo o dialogismo (BAKHTIN/VOLOSHINOV, 1959/2010, p. 116-117).

Dessa forma, entende-se que, para Bakhtin, o dialogismo tem como base a concepção sociocultural da linguagem, pois a mesma é produzida no e pelo contexto sociocultural e só pode ser compreendida enquanto interação verbal, pois todo enunciado é resposta a outro e gera outras respostas.

Relacionando o conceito de dialogismo de Bakhtin às características dos SRSs, percebemos que eles representam espaços culturais socialmente organizados, em que a base fundamental encontra-se nas interaçôes verbais entre os sujeitos. Ao postar uma mensagem ou compartilhar algum conteúdo, o locutor se dirige a alguém, no caso aos amigos ou seguidores em geral ou a alguém específico na rede de relacionamento, e também espera uma resposta, o início de um diálogo. Para Bakhtin/Voloshinov,

O diálogo, no sentido estrito do termo, não constitui, é claro, senão uma das formas, é verdade que das mais importantes, da interação verbal. Mas pode-se compreender a palavra "diálogo" num sentido amplo, isto é não apenas como a comunicação em voz alta, de pessoas colocadas face a face, mas toda comunicação verbal, de qualquer tipo que seja (BAKHTIN/ VOLOSHINOV, 1959/2010, p. 127). 
Assim, considerando que todo enunciado se dirige para alguém e demanda uma resposta, Bakhtin introduz o conceito de atitude responsiva no qual "a relação com o outro pressupóe ativismo e responsividade da parte do interlocutor" (ZOZZOLI, 2012, p. 262). Segundo Bakhtin, "toda compreensão é prenhe de resposta” (BAKHTIN, 1953/2010, p. 271), ou seja, o locutor não espera uma compreensão passiva por parte do interlocutor, mas uma resposta, seja ela de concordância, objeção ou discordância, esperase que o ouvinte torne-se falante. $\mathrm{O}$ autor reconhece, contudo, que nem sempre essa resposta é imediata, e até mesmo a não resposta já é em si uma resposta.

Nesse sentido, voltando para as características dos SRSs, toda postagem na rede de relacionamentos pressupõe uma resposta, seja ela verbal, na forma de comentário, ou não verbal. O botão "like" ou "curtir", como no SRS Facebook, por exemplo, pode significar concordância ou até mesmo indicar que aquela voz foi ouvida (a mensagem foi lida), visto que essa opção pode representar diferentes significados, i.e., "gostei", "concordo", "estou ciente", "legal", etc. Podemos entender que o próprio fato de uma postagem não receber qualquer tipo de resposta verbal ou não verbal, (nenhum "curtir"), em si já representa uma resposta dos participantes da rede de que aquele enunciado não agradou ou interessou ao grupo.

Por fim, Bakhtin reconhece que toda palavra é impregnada de palavras de outros, sendo que nosso discurso é sempre marcado pelas diversas vozes e enunciados que nos circundam. A partir dessas vozes nos construímos e construímos a nossa própria voz, caracterizando a polifonia e a heteroglossia dialogizada, nas quais a multiplicidade de vozes sociais e de diferentes textos dentro de um texto influenciam e moldam o enunciado (FARACO, 2009). Para Bakhtin,

Nosso discurso, isto é, todos os enunciados (inclusive obras citadas) é pleno de palavras dos outros, de um grau vário de alteridade ou de assimilabilidade, de um grau vário de aperceptibilidade e de relevância. Essas palavras dos outros trazem consigo a sua expressão, o seu tom valorativo que assimilamos, reelaboramos, e reacentuamos. (BAKHTIN, 1953/2010, p. 294).

Dotta e Giordan (2007) discutem o papel do diálogo na aprendizagem a distância a partir dos conceitos de polifonia e dialogismo de Bakhtin. Reconhecendo a sala de aula como um espaço de múltiplas vozes, uma 
educação dialógica buscará a construção de sentido, e, consequentemente, a aprendizagem, por meio da interação verbal e da criação de zonas de desenvolvimento proximal para mediar as atitudes responsivas dos participantes. Para os autores,

[...] a aprendizagem dialógica é um processo que promove o reposicionamento do sujeito no horizonte conceitual do outro e a apropriação de gêneros de discurso e atitudes científicas. [...], então a aprendizagem se dá a partir das interações dialógicas e da apropriação do discurso do outro (DOTTA; GIORDAN, 2007).

Ao pensarmos os SRSs como suportes para a aprendizagem no meio virtual, observamos que podem constituir ambientes para um processo de educação dialógica, voltado para o diálogo entre os participantes, que, a partir das diferentes vozes sociais presentes no ambiente virtual conduzam à construção do próprio discurso e do conhecimento.

\section{A importância das interações sociais para o desenvolvimento e a aprendizagem}

Vygotsky trouxe grande contribuição teórica para o campo da pedagogia e da educação contemporânea a partir de seus estudos sobre o desenvolvimento dos processos psicológicos superiores. Embora tenha dedicado suas pesquisas aos processos de instrução e desenvolvimento de crianças, podemos nos apropriar de diferentes conceitos, tais como o de desenvolvimento de conceitos espontâneos e científicos e de zonas de desenvolvimento real e potencial (proximal), para qualquer situação de instrução, seja ela de crianças em idade escolar, ou de jovens e adultos no ensino superior, uma vez que nos permitem compreender os processos de ensino e aprendizagem presenciais ou virtuais a partir de uma concepção sócio-histórica.

Assim como Bakhtin, Vygotsky reconhece a importância do outro para o desenvolvimento de funções mentais superiores, uma vez que o desenvolvimento e a aprendizagem se dão na atividade social cooperativa mediada pela linguagem (DANIELS, 2003). Para Vygotsky, a aprendizagem é um processo essencialmente social que "pressupõe uma natureza social específica e um processo através do qual as crianças penetram na vida intelectual daqueles que as cercam" (VYGOTSKY, 1930/1998, p. 115). Segundo ele, a aprendizagem se inicia no nível social, na interação com o outro, para só depois, então, se tornar individual. Nas palavras do autor, 
Um processo interpessoal é transformado num processo intrapessoal. Todas as funçōes no desenvolvimento da criança aparecem duas vezes: a primeira, no nível social, e, depois, no nível individual; primeiro entre pessoas (interpsicológica), e, depois, no interior da criança (intrapsicológica) (VYGOTSKY, 1930/1998, p. 75).

No contexto da educação mediada pelas novas tecnologias, principalmente no caso dos SRSs, podemos perceber claramente como a aprendizagem e a construção de conhecimento são estabelecidas por meio das trocas e interaçôes entre os participantes, primeiramente no nível social, no próprio ambiente da rede social, para depois ser internalizada individualmente por cada participante. Por meio de debates entre professor e aluno e entre os próprios alunos e/ou participantes da rede social, é possível estabelecer situaçôes de aprendizado e intercâmbio cultural que levam ao desenvolvimento do indivíduo.

Ainda considerando a importância do outro para a aprendizagem, Vygotsky desenvolveu a proposta metodológica da zona de desenvolvimento proximal (ZPD), na qual identifica dois níveis de desenvolvimento na criança. O primeiro nível diz respeito ao nível de desenvolvimento mental da criança já amadurecido, que demonstra o que ela consegue fazer por si mesma, de forma independente e o qual Vygotsky denominou de nível de desenvolvimento real (VYGOTSKY, 1930/1998, p. 111). Em contraposição, o autor identifica a zona de desenvolvimento proximal como as funções que ainda não se desenvolveram, mas se encontram em processo de maturação. Segundo o autor,

Ela é a distância entre o nível de desenvolvimento real, que se costuma determinar através da solução independente de problemas, e o nível de desenvolvimento potencial, determinado através da solução de problemas sob a orientação de um adulto ou em colaboração com companheiros mais capazes (VYGOTSKY, 1930/1998, p. 112).

O conceito de zona de desenvolvimento proximal é peça chave na teoria de desenvolvimento de Vygotsky, pois ela nos permite revelar o estado de desenvolvimento mental da criança. Além disso, o autor ressalta a importância da criação de zonas de desenvolvimento proximal na aprendizagem eficaz, afirmando que "o aprendizado desperta vários processos internos de desenvolvimento, que são capazes de operar somente quando a criança interage com pessoas em seu ambiente e quando em cooperação com seus companheiros" (VYGOTSKY, 1930/1998, p. 117/118). 
Tal conceito nos permite entender os SRSs como ambientes onde é possível criar zonas de desenvolvimento proximal que conduzirão à aprendizagem a partir da interação e colaboração entre alunos em diferentes níveis de desenvolvimento. Ao interagirem e trabalharem em colaboração com pares mais competentes (professor e outros alunos) na rede social virtual, os alunos podem desempenhar tarefas e alcançar compreensóes que talvez não fossem capazes de realizar individualmente, conduzindo-os à aprendizagem de novos conceitos e/ou conteúdos.

Zainuddin, Abdullah e Downe (2011) defendem a utilização de SRSs como suportes para a aprendizagem sob uma perspectiva vygotskyana uma vez que podem ser utilizados como ferramentas externas para a criação de zonas de desenvolvimento proximal que conduzirão à aprendizagem dos estudantes no ambiente virtual. Esse processo se dá por meio das interações entre eles utilizando diferentes ferramentas oferecidas pelo ambiente, como por exemplo, bate-papo, mural e grupos de discussão.

Outra contribuição importante de Vygotsky para a prática pedagógica e a aprendizagem diz respeito ao desenvolvimento de conceitos espontâneos e científicos, cuja compreensão, segundo o autor, deve guiar a criação de métodos eficientes para a instrução do conhecimento sistemático (VYGOTSKY, 1930/1998, p. 104). Vygotsky admite que a aprendizagem não se inicia na escola, mas sim, desde o momento do nascimento da criança (VYGOTSKY, 1930/1998, p. 110). Em sua interação com o mundo social, a criança desenvolve certos conceitos que o autor denomina de espontâneos, ou seja, conceitos do cotidiano, não-conscientes ou sistemáticos, relacionados à experiência (VYGOTSKY, 1930/1998, p. 135). Vygotsky observa a diferença entre esses conceitos e os de ordem científica, que segundo ele, compreendem um sistema hierárquico de inter-relações possibilitado pela aprendizagem escolar, que a partir da mediação do professor irá permitir a tomada de consciência (VYGOTSKY, 1930/1998, p. 115).

Vygotsky reconhece a inter-relação e interdependência entre os dois conceitos, e defende a instrução que parta dos conceitos espontâneos para que então sejam transformados em conceitos científicos, promovendo o desenvolvimento (VYGOTSKY, 1930/1998, p. 145). A esse respeito Daniels (2003) salienta que

O movimento entre professor e aluno, e entre texto escrito e conversa, é parte do processo pelo qual ferramentas conceituais cada vez mais poderosas são desenvolvidas. Desse modo, os conceitos científicos são 
desenvolvidos por diferentes níveis de diálogo: no espaço social, entre professor e aluno; e no conceitual, entre o cotidiano e o científico. O resultado é a produçãao de redes ou padrôes de conexão conceitual (DANIELS, 2003, p. 73-74).

Daniels destaca ainda que, para Vygotsky, a instrução é a força motriz para o desenvolvimento e a aprendizagem, no entanto, a instrução para Vygotsky, não consiste na simples transmissão de conceitos e/ou conteúdos, mas sim, uma prática colaborativa entre professor e criança, em que ela, trabalhando junto com o professor (par mais experiente), é capaz de resolver problemas até então impossíveis de resolver sozinha. Assim, a cooperação e a colaboração constituem componentes essenciais para o ensino/aprendizagem eficaz.

A concepção de Vygotsky acerca do ensino de conceitos científicos, e do próprio processo de ensino e aprendizagem em si, é bem oportuna para o debate sobre o modelo pedagógico ainda em voga. Embora seja amplamente reconhecida a necessidade de um modelo dialógico de educação, que parta das experiências dos próprios aprendizes, como defendido por Freire (1996), ainda é comum encontrarmos modelos de ensino altamente hierarquizados, estruturados e autoritários, que partem da simples transmissão de conceitos científicos por parte do professor, ignorando, muitas vezes, os conceitos espontâneos dos aprendizes. Quanto a isso, Vygotsky argumenta que

A experiência prática mostra também que o ensino direto de conceitos é impossível e infrutífero. Um professor que tenta fazer isso geralmente não obtém qualquer resultado, exceto o verbalismo vazio, uma repetição de palavras pela criança, semelhante à de um papagaio, que simula um conhecimento dos conceitos correspondentes, mas que na realidade oculta um vácuo (VYGOTSKY, 1930/1998, p. 104).

A utilização de SRSs no processo educacional pode contribuir para uma mudança de paradigmas. Longe de constituírem-se ambientes altamente estruturados ou hierarquizados, os SRSs compreendem ambientes onde os jovens se sentem à vontade para compartilhar suas experiências e conhecimento de mundo. Esses ambientes podem ser utilizados para a construção de conceitos científicos a partir da mediação do professor ou de pares mais experientes, conduzindo a uma maior autonomia dos estudantes e à criação de zonas de desenvolvimento proximal que irão conduzir à aprendizagem. 


\section{Metodologia e contexto do estudo}

O presente trabalho foi realizado com base em um estudo exploratório sobre a formação de um grupo no site de rede social Facebook com o objetivo de expandir as interações realizadas na sala de aula presencial. A pesquisa, de caráter interpretativista (MOITA LOPES, 1994), buscou identificar como as interações realizadas no SRS contribuíram para a construção colaborativa de conhecimento, além de refletir sobre as contribuiçôes de Bakhtin e Vygotsky apresentadas acima, que, embora não tenham sido elaborados com base em ambientes virtuais de aprendizagem, nos ajudam a compreender muitos dos fenômenos que ocorrem a partir da utilização dessas ferramentas em contextos educacionais. Como desdobramento dessa pesquisa, outro estudo paralelo, ainda não publicado, buscou identificar a visão dos alunos sobre a experiência de utilização do SRS como ambiente virtual de aprendizagem.

Os sujeitos do estudo compreendem a professora-pesquisadora e 57 alunos de um curso de graduação em Relações Internacionais em uma universidade federal que participaram da disciplina Inglês I no primeiro semestre de 2012, e que teve como conteúdo principal a discussão sobre a utilização da língua inglesa como língua de comunicação global e as relativas implicações.

A fim de complementar o conteúdo do curso com recursos multimídia, tais como vídeos, imagens e hipertextos, e ampliar a prática de comunicação em língua inglesa para além do espaço físico da sala de aula, a criação de um grupo fechado no SRS Facebook foi proposta pela professora e aprovada pela maior parte dos alunos. A participação no grupo, contudo, não foi obrigatória, sendo que dos 60 alunos inscritos na disciplina, 57 solicitaram a participação no grupo e 46 postaram ao menos uma mensagem no grupo ao longo do semestre.

O grupo criado no Facebook propôs, assim, a expansão da sala de aula presencial a partir do compartilhamento de conteúdos complementares aos materiais instrucionais principais, que compreenderam a leitura de dois livros acerca do uso da língua inglesa como língua de comunicação global (CRYSTAL, 2003) e como língua franca na negociação de conflitos (FRIEDRICH, 2007) e a apresentação de seminários sobre os temas abordados em cada capítulo. Como a sala de aula presencial não dispunha de recursos tecnológicos como computador, projetor multimídia ou acesso à Internet, foi proposto que o ambiente do SRS fosse utilizado para esse fim, permitindo aos alunos e à professora compartilhar textos, vídeos e outros 
recursos relativos ao conteúdo abordado nas aulas presenciais, além de promover a discussão destes temas utilizando a língua alvo, ou seja, todas as postagens no grupo deveriam ser feitas em língua inglesa.

Dessa forma, um dos principais objetivos na criação do grupo no SRS foi permitir uma maior interação entre os alunos, a professora, e os conteúdos, na discussão de temas relevantes para a disciplina, uma vez que o grande número de alunos em sala (60 ao total), por vezes, atrapalhava o debate em grupo. Além disso, muitos alunos mais tímidos ou com maior dificuldade na interação poderiam se sentir mais a vontade para participar dos debates virtuais, ampliando as possibilidades de participação. Por outro lado, também se objetivou a criação de um espaço dialógico e não hierárquico, onde os alunos pudessem iniciar interaçōes espontâneas utilizando a línguaalvo e compartilhar informações e conteúdos que contribuíssem para a criação de zonas de desenvolvimento proximal, conduzindo à colaboração e à aprendizagem do grupo.

No entanto, além dos objetivos propostos inicialmente, o ambiente virtual da rede social também acabou sendo utilizado para comunicação entre professora e alunos ao longo do curso e o compartilhamento de informaçóes administrativas, tais como confirmação de aulas, realização de tarefas, entre outros. $\mathrm{O}$ ambiente também foi utilizado para o compartilhamento de mensagens e conteúdos não relacionados diretamente ao conteúdo programático proposto pelo curso, tais como videoclipes de músicas, piadas, charges, etc. Contudo, a maior parte dessas mensagens foi postada em língua inglesa, gerando interação entre os alunos utilizando a língua-alvo.

$\mathrm{O}$ instrumento para a coleta de dados foi o próprio ambiente virtual da rede social, de onde foram retiradas as mensagens postadas no mural do grupo (todas em língua inglesa). Para os fins dessa pesquisa, todos os procedimentos éticos foram respeitados, como o consentimento informado dos participantes e a garantia do anonimato. Dessa forma, os nomes utilizados nas reproduções dos eventos de interação foram substituídos por nomes fictícios e as fotos dos participantes removidas como forma de preservar a identidade dos participantes.

Durante o período do curso (de abril a outubro de 2012) foram postadas 77 mensagens no grupo criado para a disciplina, das quais 44 couberam à professora e 33 aos alunos. Destas, 41 mensagens foram classificadas como relativas ao conteúdo do curso (compartilhamento de vídeos, textos, e atividades relacionadas ao tema do curso), 20 mensagens 
tiveram um cunho administrativo (solução de dúvidas sobre o curso e tarefas, compartilhamento de materiais instrucionais, etc.) e 16 mensagens caracterizaram-se como "off-topic", por não se relacionarem diretamente ao conteúdo discutido no curso, tais como músicas, charges, vídeos de humor e piadas.

Essas mensagens geraram um total de 409 comentários (respostas), tanto da própria professora quanto dos alunos, gerando um percentual de 5,31 comentários por mensagem. Também foi contabilizado um total de 214 opções de "Curtir", que como veremos a seguir, pode representar, dentre outros significados, que os alunos concordam com o conteúdo postado, ou simplesmente estão cientes da publicação.

Para os propósitos desse trabalho, foram selecionados três eventos de interação analisados à luz dos conceitos propostos por Bakhtin e Vygotsky, apresentados na seção 2, a fim de refletir sobre a possibilidade de se desenvolver uma educação dialógica e potencializar a criação de zonas de desenvolvimento proximal por meio do uso dos SRSs na educação híbrida (blended learning).

Cabe ressaltar, no entanto, que, como o objetivo principal da utilização do grupo foi o de ampliar as interaçóes dos alunos no ambiente virtual, expandindo as oportunidades de aprendizado do conteúdo da disciplina, não foi realizado, dentro do ambiente virtual do SRS, qualquer tipo de correção da utilização das estruturas da língua inglesa, como gramática, vocabulário e/ou ortografia. Um trabalho paralelo de conscientização sobre gêneros discursivos (gênero acadêmico X digital) e a importância da correção da estrutura linguística para os processos de comunicação na área de Relações Internacionais foi realizado nas aulas presenciais sem expor os "erros" dos alunos em relação à utilização da língua-alvo no ambiente virtual. O discurso dos alunos é aqui reproduzido tal qual postado pelos próprios alunos no mural do SRS.

\section{Discussão dos resultados}

Com base no corpo teórico que norteia nosso pensamento (dialogismo, atitude responsiva, zona de desenvolvimento proximal, conceitos espontâneos e científicos), buscamos identificar a ocorrência de tais concepçóes na utilização do SRS como ambiente virtual de aprendizagem. Este passo é fundamental para promover maior compreensão dos processos de ensino e aprendizagem que podem ser potencializados pela ferramenta tecnológica. 
No primeiro episódio de interação, reproduzido na Figura 1, uma aluna inicia o processo de interação verbal no ambiente ao apresentar um arquivo de vídeo que serviria para ilustrar a discussão do tema apresentado pelo grupo na aula, em forma de seminário, sobre o futuro da língua inglesa como língua de comunicação global.

Raquel

27 de setembro de 2012 - Rio de Janeiro

Guys, as we don't have the equipment to show this video in class, i will post it here. It has to do with the presentation of my group

Language adopts a global role once it is needed for communication.

English plays a role as a global language since imperialism. It is nowadays used not only for communication, but also for negotiations between countries. With this we have a better relation between nations. All culture, knowledge and economy exchanges happens thanks to the communication provided by the languages. But language is always changing, and with this its power. What is left for us is a discussion about which will be the next global language, or if english will still play this important global role?

http://www.youtube.com/watch

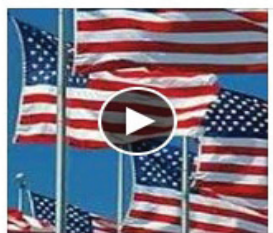

The Future of the English Language Words, phrases and idioms reflect the world around us. If you don't believe us, check out "word of mouth" on radio 4: http://www.bbc.co.uk/radio $4 /$ factual/wor...

Descurtir - Comentar - Compartilhar

B Você curtiu isso.

Visualizado por 31

Professora: Great video, Raquel This debate is really

2 de outubro de 2012 às $14: 48$ - Curtir - 31

Patrícla: And this is a debate that always comes back because other countries are growing, and as has happened in the past with other languages such as Latin and French, is a concern that can also happen with English ( to be replaced)

2 de outubro de 2012 às $14: 53$ - Descurtir - B2

Raquel: And I believe that it will happen with English. I don't think it is irreplaceable. As we see China's growth, I think that, in the future, people may see Mandarin becoming a global language. 4 de outubro de 2012 às 09:59 - Curtir

José: I disagree with you, Pat I I think English will always be the global language. I don't think it will lose importance in the world. I can't see Mandarin as a global language, even with China's growth 4 de outubro de 2012 às 10:09 - Curtir

Raquel: You can't see it now, because you are accostumed with that. But people, probably, couldn't imagine either USA being such a powerful country and English being a global language as today happens. 4 de outubro de 2012 às 10:16 - Curtir

José: Imagine everyone talking Mandarin... crazy!

4 de outubro de 2012 às 10:19 - Curtir

FIGURA 1- Episódio de interação 1 
Podemos perceber como o discurso da aluna Raquel, em sua enunciação, é marcado por outros enunciados anteriores (discussões em sala de aula e leituras de textos), caracterizando a voz de Bakhtin de que "cada enunciado é um elo na corrente complexamente organizada de outros enunciados" (BAKHTIN, 1953/2010). A aluna também propõe um debate sobre qual será a próxima língua global. $\mathrm{O}$ enunciado deixa claro a sua expectativa de uma atitude responsiva por parte dos interlocutores (membros do grupo) ao propor a discussão sobre uma possível nova língua global ou se o inglês continuará a exercer este papel global, discussão que já havia sido iniciada na sala de aula presencial e continuou no ambiente virtual através das respostas de Patrícia e José ao enunciado.

Uma ferramenta interessante do SRS é que este nos permite identificar quantas pessoas visualizaram a postagem, no caso do episódio de interação acima, 53 participantes (dos 58 membros do grupo), sendo que apenas três emitiram uma resposta verbal ao enunciado, e um deles estabeleceu um breve diálogo com o locutor. Nesse sentido, percebemos que a maior parte dos estudantes assumiu uma atitude responsiva silenciosa, não se posicionando em relação à discussão proposta pelo grupo. Como Bakhtin (1953/2010, p. 272) esclarece, a não resposta já é em si uma resposta, ou seja, o fato de apenas três alunos terem se engajado na discussão proposta pelo grupo evidencia que os demais membros do grupo, apesar de terem visualizado a publicação, mas não necessariamente lido seu conteúdo, preferiram não participar do debate, emitindo uma atitude responsiva silenciosa.

Similarmente, Bakhtin afirma que a atitude responsiva envolve uma compreensão ativa do enunciado e uma resposta a ele, seja ela de concordância ou não, que expressará uma apreciação valorativa do interlocutor. Nesse evento de interação, há uma discordância entre os alunos quanto ao fato de o mandarim vir a se tornar nova língua global, o que é de extrema importância para uma situação de ensino e aprendizagem, pois é a partir do conflito de ideias e do debate que se pode construir o conhecimento colaborativamente.

Dois pontos são interessantes de se comentar em relação a esse episódio de interação e aos que virão a seguir. $\mathrm{O}$ primeiro diz respeito à noção de comunicação síncrona e assíncrona, característica dos processos de comunicação mediados por computador. $\mathrm{O}$ fato de a maior parte dos alunos possuir perfil na rede social escolhida (Facebook) e fazer uso diário e intenso da ferramenta permitiu uma maior comunicação síncrona no 
processo dialógico, fato percebido nas datas e horários das postagens, muitas vezes realizadas sincronicamente. $\mathrm{O}$ segundo é relativo à própria linguagem típica dos SRSs, uma vez que a linguagem utilizada no diálogo virtual nesses ambientes pode ser percebida como uma linguagem informal e cotidiana, bem similar à fala oral, marcada por pausas, representadas pelo uso de reticências, uso de emoticons, etc.

O próximo episódio de interação (Figura 2) demonstra a transformação de conceitos espontâneos em conceitos científicos, conforme proposto por Vygotsky (1930/1998). Ao iniciar uma discussão sobre o papel da língua inglesa na negociação e resolução de conflitos, com base na leitura do livro "Language, Negotiation and Peace: the use of English in conflict resolution" de Patricia Friedrich (2007), a professora propõe uma discussão sobre os significados das palavras "língua", "negociação", "paz" e "conflito" a fim de iniciar uma "tempestade de ideias" (brainstorming) antes da leitura e discussão do livro pela turma. Ou seja, a professora busca que os alunos explicitem os conceitos espontâneos em relação a estas palavras (signos) antes da apresentação dos conceitos científicos na aula presencial e na leitura do texto. Para isso, no enunciado da interação virtual, a professora pede que os alunos definam o que as quatro palavras significam para eles, podendo estes definir as quatro palavras ou escolher apenas uma delas para o debate.

A primeira aluna a participar do episódio de interação, Juliana, pergunta, se o objetivo do diálogo é oferecer as definiçōes de acordo com o conhecimento prévio dos alunos em relação a cada palavra (conceito espontâneo) ou o conceito científico, adquirido após a leitura do texto proposto. A professora, interessada em estabelecer a transição entre os conceitos espontâneos e científicos, esclarece que naquele momento estava interessada no conceito não sistemático, a partir da visão pessoal de cada aluno, para só depois passar ao conceito científico.

Juliana, então, sai da conversa e, posteriormente, Letícia retoma a interação proposta pela professora, trazendo seu conceito de linguagem. A professora responde e estabelece uma zona de desenvolvimento proximal com a aluna, que servirá também para os demais participantes da rede social, fazendo a transição dos conceitos espontâneos para os científicos. 
Hey, guys, next class we're starting a new discussion related to language and relations among countries. In order to start our discussion, I'd like you to define the following words: : LANGUAGE, NEGOTIATION, PEACE, CONFLICT. What do they mean to you? You can define all four words or choose one and explain it, ok? Looking forward to this debate.

\section{Visualizado por 31}

Jullana: do we have to explain it in our point of view, freely, or we have to read the first chapter and then explain what we understand from the reading? 18 de setembro de 2012 às $15: 02$. Curtir

Jullana: and about the answers, we have to post it here or we are just going to discuss in class?

18 de setembro de 2012 às 15:03 - Curtir

Professora: The idea is that you do it freely, as you understand them, Jullana This will be a good warm up for our discussion based on the reading next class. So we can start the discussion/definitions here in the group and continue them in class.

18 de setembro de 2012 às $15: 04$ - Curtir - $\mathbf{O}_{1}$

Leticla: In my opinion, language is the best way to communicate. Since the emergence of USA as a great power, the French lost the dominant language position in IR and began to be replaced by English. The consensus on using a main language greatly facilitated communication between people.

But language it's much more than just writing and speaking because even without fluency in a language other than the native, people will find a way to communicate and express themselves when necessary.

This form of communication is called nonverbal language and uses symbols, images, mime, painting, body language, dance and so on.

The nonverbal language can be seen even in animals! Also, it's commom for people use mixed language that is the simultaneous use of verbal and nonverbal language.

18 de setembro de 2012 às 21:44 - Descurtir - 12

Professora: Thank you for sharing your ideas on language,

Letícla You mentioned two important issues to our discussion: the means of communication and non-verbal language, as we usually associate language to written or spoken texts. Another interesting point... Ver mais 19 de setembro de 2012 às $15: 21$. Curtir

Letícia: "Linguagem": universal and abstract ability of every human being. "Linguagem" is a natural ability that humans have to communicate, whether through words, gestures, images, sounds, expressions, and so on.

"Lingua": local and concrete ability to particular people, or who is willing to learn the grammatical rules of a specific language.. "Lingua" is the set of signals that some people use to communicate; are the grammar rules. 20 de setembro de 2012 às 14:54 - Descurtir - B1

\section{FIGURA 2 - Episódio de interação 2}


A professora propõe ainda, com base nos conceitos espontâneos sobre linguagem, uma reflexão sobre a diferença entre os vocábulos "língua" e "linguagem", que embora em português constituam duas palavras diferentes, em inglês os conceitos são expressos pelo mesmo signo "language". Nesse momento, a aluna parece recorrer ao significado de cada signo conforme a definição cristalizada do dicionário, o conceito científico, apresentando a definição de cada um dos signos em português. A interação no ambiente virtual é interrompida e retomada posteriormente na sala de aula presencial, quando a professora retoma a discussão inicial proposta no ambiente do SRS, provocando a discussão sobre os conceitos espontâneos de cada um dos signos (língua, negociação, paz e conflito) e a discussão dos conceitos científicos propostos por Friedrich (2007) no texto indicado para leitura.

Por fim, o último episódio de interação é constituído por uma atividade formal realizada no ambiente do SRS. A atividade consistiu em cada aluno escolher três vídeos (de um total de 7), cujos temas consistiam em apresentaçôes do autor David Crystal sobre o uso do inglês como língua global e documentários sobre variação linguística, como por exemplo Singlish, Hindish e Ebonics. Os alunos deveriam estabelecer uma atitude responsiva comentando cada um dos vídeos assistidos e emitindo sua apreciação crítica (de valor) em relação aos enunciados (concordância, discordância, etc.). Deveriam também situar a relação entre o vídeo, as discussões realizadas em aula e a leitura do livro "English as a Global Language" (CRYSTAL, 2003), além de expor sua relevância para a área de Relaçōes Internacionais (área de estudo principal). A atividade objetivou a criação de zonas de desenvolvimento proximal entre os alunos e os especialistas, no caso os locutores dos vídeos, e entre os próprios alunos que, em colaboração, comentaram os vídeos interagindo uns com os outros. A atividade também buscou, como mencionado anteriormente, estimular a atitude responsiva dos alunos e uma relação dialógica entre o conteúdo estudado (conceitos científicos) e o conhecimento prévio dos alunos (conceitos espontâneos), tornando a aprendizagem situada e significativa.

As Figuras 3 e 4 ilustram parte das interaçóes realizadas no desenvolvimento da atividade de um total de 15 respostas à mensagem original (enunciado). 


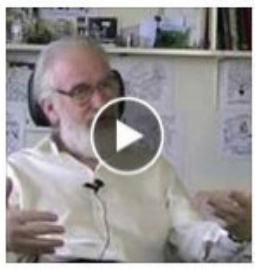

David Crystal - Is control of English shifting away from British and American native speakers?

Is control of English shifting away from British and American native speakers? Global English with...

Curtir - Comentar - Compartilha

$\checkmark$ Visualizado por 31

Janaína: English were expanding as a global language as the United States were becoming the most important country in the globalized world. As the ithat Nation influence in world's economy, politics, culture and many more subjects of a country's life was increasing the English was more and more necessary to the "survival" of globalization's relations (and that influence can be noticed even before the globalization, being an example of that the imperialism in Africa and the South African language that is english). With that the number of people that speaks english as a second language had an enlargement as it was never saw in the history before. Some of the consequences of that is the "mixed english" that happens to happen with noun-natives, but I once more disagree with David Crystal's opinion. Globalization not only expanded the english as a global language, but the technologies that were developed, as the internet, in it propitiated a better intersection between noun-natives and natives, and is that the major factor that for me will not make english escape from the control of the native speakers. Of course that some changes will happen, but it is the influence that the native makes in the noun-speaker that will prevail and not the opposite.

14 de junho de 2012 às 00:42 - Descurtir - 01

FIGURA 3 - Episódio de interação 3 (parte 1)

Novamente, é possível perceber a "voz de outrem" no discurso dos alunos ao agirem responsivamente sobre o enunciado do vídeo proposto. A voz do autor David Crystal e outras vozes com as quais os alunos dialogaram em diversos momentos de sua vida escolar e acadêmica impregnam as vozes dos participantes ao relacionarem o conteúdo do vídeo com os conceitos anteriores, em relação ao campo de conhecimento de Relaçôes Internacionais e de outras disciplinas como História e Sociologia.

$\mathrm{Na}$ segunda parte do evento de interação (Figura 4), a professora também age responsivamente, interagindo com os alunos e propondo novas questôes para debate e novas relações interligando conceitos espontâneos e científicos, como no caso do conceito dos círculos concêntricos propostos por Kashru (ver CRYSTAL, 2003) em relação ao uso da língua inglesa como língua materna, segunda língua e como língua estrangeira, discutido previamente em aula. 
Renan: I could not agree more with David Crystal. The evolution of English language is being more influenced by non-native speakers than the opposite. This fact has a reasonable explanation: there are more non-native English speakers than native English speakers in the world. As a lingua franca, English language reached a huge spreading level with globalization, wich brought a myriad of new cultural factors from every corner of the world to the development of the English language and thus adding a bunch of new features to the way of speaking and writing in English. In fact, this English language metarmorphosis is nothing more than a kind of adptation of the language to the cultural variety of the world. It would be impossible to English language remains exactly the same contacting so many different people, with so many different worldviews influenced by cultural specificities. In the end, the English language become richer and more beautiful with these transformations.

8 de setembro de 2012 às 14:59 - Descurtir - 1

Professora: Good point about proficiency exams, Marla . They do standardize the language according to native speakers usages. Although there's a great video where an English teacher advocates against the use of these exams and the imposition of English language as linguistic imperialism and the death of many languages. 10 de setembro de 2012 às 22:08 - Descurtir - 11

Professora: Good discussion! How can you relate your ideas to the "three circles of English" (Kachru, 1988) presented by Crystal (2003)? And how does it connect to the field of IOnterantional Relations? 10 de setembro de 2012 às 22:11 - Curtir

Renata: David Crystal stated that the number of non-native speakers is bigger than the number of native ones and this fact is easily seen in the three circles of English organized by Kachru. The non-natives speakers are represented in the outer circle and in the expanding circle and the both together have much more speakers than the inner circle, which is constituted by native speakers. Indeed, comparing with the others circles countries, nowadays, the expanding circle countries, where English is a foreign language, have larger use of the language. Consequently, these countries are making a much more important contribution to the maintenance of English as a global language.

In the field of International Relations, the Standard English has an important status, thus, in my opinion, the inner circle models will continue to have a preponderance. Even though the new varieties bring new uses of English to an international communication, it is impossible to learn all the existing varieties, but at least, to have a successful communication, we as future internationalists, should be aware of these new uses and respect them.

13 de setembro de 2012 às 11:56 - Descurtir - 11

FIGURA 4 - Episódio de interação 3 (parte 2)

Os três episódios de interação apresentados nesse artigo representam apenas uma pequena amostra de como a utilização dos SRSs pode contribuir para expandir as interações entre alunos, professor e conteúdo para além da sala de aula, ampliando o contexto de ensino-aprendizagem. Além disso, o SRS utilizado favoreceu a criação de zonas de desenvolvimento potencial e a elaboração de conceitos espontâneos em científicos, favorecendo o desenvolvimento e aprendizagem dos participantes. Ao se caracterizar por uma premissa de atitude responsiva por parte dos participantes da rede, o ambiente estimulou o diálogo e a interação, favorecendo o compartilhamento de informações e a construção colaborativa do conhecimento, a partir da busca e compartilhamento de conteúdos complementares aos tópicos trabalhados na sala de aula presencial. 


\section{Considerações finais}

O trabalho aqui apresentado objetivou refletir sobre a potencialidade dos SRSs se constituírem como espaços virtuais de ensino e aprendizagem, de forma a promover o diálogo e a interação entre alunos e professor na construção colaborativa do conhecimento. Nesse sentido, as contribuiçōes sócio-históricas de Vygostsky e Bakhtin, relativas aos conceitos de atitude responsiva, dialogismo, conceitos espontâneos e científicos e zona de desenvolvimento proximal, constituem referencial significativo na busca por processos de ensino e aprendizagem que promovam uma maior participação do estudante na construção do conhecimento em rede no contexto das tecnologias digitais.

No caso investigado, o SRS se mostrou como um ótimo recurso para ampliar e potencializar as interações entre os estudantes, dado o grande número de alunos em sala de aula. Além disso, por essas tecnologias fazerem parte do cotidiano da maior parte dos jovens, pode-se ampliar o canal de diálogo e interação entre professor, estudantes e conteúdo. Da mesma forma, pode-se estimular uma participação mais ativa e colaborativa que em contextos de aprendizagem presencial, nos quais alguns estudantes podem se sentir tímidos em falar publicamente.

A análise destes e outros eventos de interação no SRS evidenciou que alguns alunos que demonstraram pouca participação oral nas aulas presenciais, tais como José no episódio de interação 1 e Letícia no episódio de interação 2, entre outros, encontraram no SRS, mesmo que de forma reduzida, um espaço para expressar suas ideias e interagir com a professora, outros alunos e o próprio conteúdo. Por outro lado, o espaço também foi construído como forma de estimular a pesquisa e compartilhamento de informações por parte dos alunos, que deveriam pesquisar recursos multimídia (vídeos, textos e imagens) para complementar as apresentações orais realizadas nos seminários durante as aulas presenciais, e propor e mediar a discussão com os demais alunos, como ilustrado no episódio de interação 1, o que contribuiu para o enriquecimento dos debates e a aprendizagem colaborativa.

Dessa forma, a atitude responsiva dos participantes e as zonas de desenvolvimento potencial criadas no ambiente virtual contribuíram para a construção colaborativa do conhecimento e a construção de conceitos científicos, além de expandir significativamente as interações sociais para além do espaço físico da sala de aula. 
Como limitaçôes do estudo, cabe destacar o seu caráter exploratório e o fato de o ambiente virtual do SRS não ter sido utilizado como ambiente formal de aprendizagem, tendo contado com a participação voluntária dos alunos. Apesar dessas limitações, o estudo considerou que o objetivo da criação do ambiente (expandir as interaçôes da sala de aula presencial e permitir a utilização de diferentes linguagens e mídias) contribuiu para a construção da aprendizagem colaborativa a partir da ampliação das interações entre os alunos, o conteúdo e a professora, potencializadas pelo ambiente de rede social, demonstrados no compartilhamento de informações e conteúdos e na discussão dos mesmos.

\section{Referências}

BAKHTIN, M. [1953] Estética de Criação Verbal. 5aed. São Paulo: Martins Fontes, 2010.

BAKHTIN, M. (VOLOSHINOV, V. N.) [1929]. Marxismo e filosofia da linguagem. 14a ed. São Paulo: Hucitec, 2010.

BOYD, D. M.; ELLISON, N. B. Social network sites: definition, history and scholarship.In: Journal of Computer-Mediated Communication. Indiana, v. 13, n.1, article 11, October, 2007. Disponível em: http://onlinelibrary.wiley.com/ doi/10.1111/j.1083-6101.2007.00393.x/pdf. Acesso em: 20 jun. 2014.

BUZZETTO-MORE, N. A. Social Networking in Undergraduate Education. In: Interdisciplinary Journal of Information, Knowledge, and Management. v. 7, 2012. Disponível em: http://www.ijikm.org/Volume7/IJIKMv7p063-090Buzzetto611. pdf Acesso em: 20 jan. 2013.

CRYSTAL, D. English as a Global Language. Cambridge: CUP, 2003.

DANIELS, H. Vygotsky e a pedagogia. São Paulo: Edições Loyola, 2003.

DOTTA, S.; GIORDAN, M. O papel do diálogo em educação a distância. In: VIII ENIL ENCONTRO NACIONAL DE INTERAÇÃO EM LINGUAGEM VERBAL E NÃO-VERBAL, 2007, São Paulo. Anais eletrônicos... São Paulo: USP, 2007. Disponível em: http://www.fflch.usp.br/dlcv/enil/pdf/39_Silvia_D_e_ Marcelo_G.pdf Acesso em: 20 jan. 2014.

FARACO, C. A. Linguagem \& Diálogo - as ideias linguísticas do círculo de Bakhtin. São Paulo: Parábola Editorial, 2009.

FREIRE, P. Pedagogia da autonomia: saberes necessários á prática educativa. 29a ed. São Paulo: Editora Paz e Terra, 1996. 
FREITAS, M. T. A. Nos textos de Bakhtin e Vygotsky: um encontro possível. In: BRAIT, B. (Org.) Bakhtin, dialogismo e construção de sentido. Campinas, SP: Unicamp, 1997.

FRIEDRICH, P. Language, Negotiation and Peace: The Use of English in Conflict Resolution. New York: Continuum, 2007.

KENT, M. Changing the Conversation: Facebook as a Venue for Online Class Discussion in Higher Education. In: MERLOT Journal of Online Learning and Teaching. v. 9, n. 4, p. 546-565, 2013. Disponível em: http://jolt.merlot.org/ vol9no4/kent_1213.pdf Acesso em: 16 jul. 2014.

LEMOS, A. Cibercultura: Alguns pontos para compreender a nossa época. In: LEMOS, A.; CUNHA, P. (Orgs). Olhares sobre a Cibercultura. Porto Alegre: Sulina, p. 11-23, 2003.

LÉVY, P. Cibercultura. 3a ed. São Paulo: Ed. 34, 2010.

MEISHAR-TAL, H.; KURTZ, G.; PIETERSE, E. Facebook Groups as LMS: A Case Study. In: The International Review of Research in Open and Distance Learning. v. 13, n. 4, 2012. Disponível em: http://www.irrodl.org/ index.php/irrodl/article/view/1294 Acesso em: 16 jul. 2014.

RABELLO, C.; HAGUENAUER, C. Sites de Redes Sociais e Aprendizagem: Possibilidades e Limitaçôes. In: HAGUENAUER, C.; CORDEIRO FILHO, F. (Orgs). Ambientes Virtuais de Aprendizagem: dos SGAs aos games e à realidade virtual. Curitiba: Editora CRV, p. 63-77, 2012.

RECUERO, R. Redes sociais na Internet. Porto Alegre: Sulina, 2009.

SELWYN, N. Faceworking: exploring students' education-related use of Facebook. In: Learning, Media and Technology. London, v. 34, n. 2, p. 157-174, 2009. Disponível em: http://www.tandfonline.com/doi/abs/10.1080/17439880902923622\#preview Acesso em: 16 jul. 2014.

SIEMENS, G. New structures and spaces of learning: the systemic impact of connective knowledge, connectivism, and networked learning. Encontro sobre Web 2.0. Braga: Universidade do Minho, 2008. . Disponível em: http://elearnspace.org/ Articles/systemic_impact.htm Acesso em: 20 jan. 2014.

SIEMENS, G.; WELLER, M. Higher education and the promises and perils of social networks.In: Revista de Universidad y Sociedad del Conocimiento. Barcelona, v. 8, n. 1, p. 164-170, January 2011. Disponível em: http://rusc.uoc.edu/ojs/index. $\mathrm{php} /$ rusc/article/view/v8n1-globalizacion-e-internacionalizacion-de-la-educacionsuperior/v8n1-siemens-weller-eng Acesso em: 20 jan. 2014.

TOWNER, T. L; MUÑOZ, C. L. Facebook and education: a classroom conection? In: WANKEL, C. (Ed.). Educating educators with social media. Bingley: Emerald, 2011. 
VIDAL, C. E.; MARTİNEZ, J. G.; FORTUÑO, M. L.; CERVERA, Mercè. University students' attitudes towards and expectations of the Educational use of social netwoks.In: Revista de Universidady Sociedad del Conocimiento. Barcelona, v. 8, n. 1, p. 186-199, 2011. Disponível em: http://rusc.uoc.edu/ojs/index.php/rusc/ article/view/v8n1-espuny-gonzalez-lleixa-gisbert/v8n1-espuny-gonzalez-lleixagisbert-eng Acesso em: 16 jul. 2014.

VYGOTSKY, L. S. [1930] A formação social da mente. São Paulo: Martins Fontes, 1998.

VYGOTSKY, L. S. [1926] Psicologia pedagógica. São Paulo: Martins Fontes, 2001. WANG, Q.; WOO, H. L.; QUEK, C. L.; YANG, Y.; LIU, M. Using the Facebook group as a learning management system: an exploratory study.In: British Journal of Educational Technology. v. 43, n. 3, p. 428-438, 2012. Disponível em: http:// onlinelibrary.wiley.com/doi/10.1111/bjet.2012.43.issue-3/issuetoc Acesso em: 16 jul. 2014.

ZAINUDDIN, S.; ABDULLAH, A.; DOWNE, A. Social Networking Sites For Learning: A Review From Vygotskian Perspective. In: INTERNATIONAL CONFERENCE ON TELECOMMUNICATION RECHNOLOGY AND APPLICATIONS, 5., 2011, Singapore. Anais eletrônicos... Singapore: IACSIT Press, 2011. Disponível em: http://www.ipcsit.com/vol5/7-icccm2011-a032.pdf Acesso em: 20 jan. 2014.

ZOZZOLI, R. M. D. A noção de compreensão responsiva ativa no ensino e na aprendizagem.In: Bakhtiniana, São Paulo, v. 7 n. 1, p. 253-269, Jan/Jun, 2012. Disponível em: http://revistas.pucsp.br/index.php/bakhtiniana/article/view/8943 Acesso em: 20 jan. 2014.

Data de submissão: 02/10/2014. Data de aprovação: 30/03/2015. 